\title{
Resgate, apreensão e destinação da herpetofauna pelos órgãos de fauna na região metropolitana do Recife, Pernambuco: contribuição para conservação
}

O tráfico de animais, a introdução de espécies exóticas e a destruição de hábitats são fatores que levam à distúrbios na biodiversidade, principalmente em grupos sinantrópicos, como vários répteis e anfíbios. Diante disto, este trabalho teve como objetivo realizar um diagnóstico da herpetofauna resgatada, apreendida, recebida e destinada pelos órgãos de fauna responsáveis répteis e anfibios. Diante disto, este trabalho teve como objetivo realizar um diagnóstico da herpetofauna resgatada, apreendida, recebida e destinada pelos órgãos de fauna responsáveis em Pernambuco entre os anos de 2010 e 2014. Foram analisados 1369 boletins de ocorrência (B.O.), com um total de 1793 indivíduos, divididos em 24 táxons ( $21,3 \%$ testudines, $16,2 \%$
crocodilianos, $11,6 \%$ lagartos, $50,6 \%$ serpentes e $0,1 \%$ anfisbenas). As principais espécies registradas foram a Boa constrictor ( $n=429)$, Caiman latirostris ( $n=295)$, Chelonoidis sp. ( $n=184$ ), Iguana iguana ( $n=154)$ e Amphisbaena sp. ( $n=2)$. Entre as espécies consideradas com maior grau de ameaça, foram recebidos Eretmochelys imbricata e Podocdemis unifilis (espécie exótica para fauna da região). A maioria dos registros veio do município de Recife $(24,1 \%)$. Foi observado um maior número de resgates na época chuvosa, principalmente para os crocodilianos e as serpentes. Testudines foi o grupo com maior número de apreensões e entregas voluntárias ( $n=33$ e 90 , respectivamente), possivelmente por ser o mais associado a pets. De maneira geral, o tráfico de animais é um problema para os órgãos ambientais no estado de Pernambuco e as políticas públicas precisam ser mais eficientes. Há também necessidade de melhor aparato estrutural e de pessoal para tornar mais eficiente a identificação e o manejo (captura e sotura) dos animais resgatados, bem como o incentivo a ações educativas com a população.

Palavras-chave: Fauna urbana; Tráfico de Animais; Biodiversidade; Urbanização.

\section{Rescue, seizure and disposal of herpetofauna by fauna agencies in the metropolitan region of Recife, Pernambuco: contribution to conservation}

\begin{abstract}
Animal trafficking, the introduction of exotic species and the destruction of habitats are factors that lead to disruptions in biodiversity, especially in synanthropic groups, such as reptiles and amphibians. In view of this, this work aimed to carry out a diagnosis of the herpetofauna rescued, seized, received and destined by the responsible fauna agencies in Pernambuco between 2010 and 2014. 1369 police reports (BO) were issued, with a total from 1793 we have, divided into 24 taxa ( $21.3 \%$ testudines, $16.2 \%$ crocodilians, $11.6 \%$ lizards, 50.6\% snakes and $0.1 \%$ amphisbeans). The main species were Boa constrictor $(n=429)$, Caiman latirostris $(n=295)$, Chelonoidis sp. $(n=184)$, Iguana iguana $(n=154)$ and Amphisbaena sp. $(n=2)$. Among the species amphisbeans). The main species were Boa constrictor $(n=429)$, Caiman latirostris $(n=295)$, Chelonoidis sp. $(n=184)$, Iguana iguana $(n=154)$ and Amphisbaena sp. $(n=2)$. Among the species
evaluated with the highest degree of threat, Eretmochelys imbricata and Podocdemis unifilis (an exotic species for the region's fauna) were received. Most records came from the city of evaluated with the highest degree of threat, Eretmochelys imbricata and Podocdemis unifilis (an exotic species for the region's fauna) were received. Most records came from the city of and delivery ( $n=33$ and 90 , respectively), possibly because it is most associated with pets. In general, animal trafficking is a problem for environmental agencies in the state of Pernambuco and public policies that are more efficient. There is also a need for better structural and personnel apparatus to make the identification and handling (capture and burying) of rescued animals more efficient, as well as the encouragement of educational actions with the population.
\end{abstract}

Keywords: Urban fauna; Animal Trafficking; Biodiversity; Urbanization.

Topic: Conservação da Biodiversidade

Reviewed anonymously in the process of blind peer
Received: 03/04/2021

Approved: 28/04/2021
Mayara Gabrielly Negromonte (iD)

Universidade Federal Rural de Pernambuco, Brasil

http://lattes.cnpq.br/3754426839809563

http://orcid.org/0000-0002-9419-4146

mayaragnegromonte@gmail.com

Paulo Braga Mascarenhas Junior

Universidade Federal Rural de Pernambuco, Brasil

http://lattes.cnpq.br/2036444543288928

http://orcid.org/0000-0002-1292-9904

paulobragam16@gmail.com

Ednilza Maranhão dos Santos (D)

Universidade Federal Rural de Pernambuco, Brasil

http://lattes.cnpq.br/5812920432455297

http://orcid.org/0000-0001-9214-1131

ednilzamaranhao@gmail.com

DOI: 10.6008/CBPC2179-6858.2021.004.0016
Jozelia Maria de Sousa Correia (iD)

Universidade Federal Rural de Pernambuco, Brasil

http://lattes.cnpq.br/7425120526391209

http://orcid.org/0000-0003-0320-4490

jozeliac@hotmail.com
Referencing this:

NEGROMONTE, M. G. S.; MASCARENHAS JUNIOR, P. B.; SANTOS, E. M.; CORREIA, J. M. S.. Resgate, apreensão e destinação da herpetofauna pelos órgãos de fauna na região metropolitana do Recife, Pernambuco: contribuição para conservação. Revista Ibero Americana de Ciências Ambientais, v.12, n.4, p.176-193, 2021. DOI: http://doi.org/10.6008/CBPC2179-6858.2021.004.0016 


\section{INTRODUÇÃO}

O Brasil é um dos países com maior biodiversidade, estando presente em seu território cerca de 10\% da fauna global (SANTOS, 2009) e a maior diversidade de répteis e anfíbios do mundo, contanto com 1.875 táxons (1.080 espécies de anfíbios e 795 de répteis) (COSTA et al., 2018). Apesar desta grande riqueza, a intensificação das ações antrópicas, vem colocando em risco a conservação de várias espécies, principalmente no que se refere ao tráfico, introdução de espécies exóticas ou modificação e destruição das paisagens naturais, cenário bastante evidenciado na região nordeste do país. Em 2018, o Centro Nacional de Pesquisa e Conservação de Répteis e Anfíbios (RAN) coordenou a avaliação dos répteis e anfíbios ameaçadas no Brasil. Das 732 espécies de répteis avaliadas, 80 espécies (11\%) são reconhecidas como ameaçadas no Brasil. No tocante aos anfíbios, das 973 espécies avaliadas, 41 espécies (4,2\%) foram consideradas ameaçadas de extinção (ICMBio, 2018). O Estado de Pernambuco, em 2017, homologou a Lista Estadual Oficial de Espécies da Fauna Ameaçadas de Extinção - Répteis, sendo avaliados 126 espécies, das quais, 22 delas foram consideradas ameaçadas de extinção.

A herpetofauna, termo genérico designado para répteis e anfíbios é formada por um complexo grupo de organismos (POUGH et al., 2008) que ocorre em quase todos os ecossistemas brasileiros, com maior diversidade e abundância nas regiões mais quentes (MARTINS et al., 2008). Estes animais apresentam fundamental importância nos ecossistemas em que estão inseridos, funcionando, por exemplo, como controladores de cadeias alimentares (TORRES, 2012; CARREIRA et al., 2018), na dispersão de frutos e sementes (MARTINS et al., 2008; BUJES, 2010; LUCHESE, 2013; RODRIGUES, 2016), na alteração e formação de microambientes (NAVEGA-GONÇALVES, 2004; FRAGA et al., 2013; MOURA et al., 2012; MELGAREJOGIMÉNEZ, 2012; NAVEGA-GONÇALVES et al., 2013, SOMAWEERA et al., 2020). Além disso, vários organismos podem ser considerados como bioindicadores devido à sensibilidade a mudanças ambientais (RIBEIRO, 2017) e apresentar alto valor econômico, seja no mercado de pets (MARQUES et al., 2007), no consumo de subprodutos oriundos do abate (CARREIRA et al., 2018), na bioprospecção e usados popularmente em vestimentas e na medicina popular (AMARAL, 2019).

Assim como na maioria dos centros urbanos, problemáticas ambientais são comumente observadas. A exemplo disso, está o tráfico de animais silvestres, que é um dos maiores fatores de perturbação da biodiversidade global (LOPES, 2002). No Brasil, cerca de 38 milhões de espécimes são retirados de seus hábitats anualmente, tendo o corredor norte-sul como principal caminho, e as regiões Nordeste, Norte e Centro-Oeste como os principais pontos de retirada de animais do ambiente natural (ABDALA, 2007; PAGANO et al., 2009; PETTER, 2013). No estado de Pernambuco, na Região Metropolitana do Recife, foram aapreendidos mais de 100 mil animais provenientes do tráfico no ano de 1990, principalmente nas cidades de Petrolina e Recife (ELABRAS, 2003; RENCTAS, 2001; PAGANO et al., 2009). Estima-se que apenas $10 \%$ dos animais traficados não venham à óbito antes de chegar ao destino final (PAGANO et al., 2009).

Além do trânsito de fauna pelo tráfico, outro fator que influencia na conservação de espécies nativas é a introdução de espécies exóticas. É comum observar a aquisição de animais exóticos para criação como 
pets (NASSARO, 2001; KUHNEN \& KANAAN, 2014) e em alguns casos, os tutores abandonam os animais em instituições como Centros de Triagem de Animais Silvestres (CETAS), zoológicos e até mesmo solturas na natureza (NASSARO, 2001; SEBA, 2014). Um dos principais problemas é que uma espécie exótica em um ecossistema diferente da sua distribuição natural pode ocasionar um desequilíbrio ambiental, por meio de competição com espécies nativas, podendo causar declínio das populações locais (NASSARO, 2001).

Em Pernambuco, a população desses animais é diretamente influenciada pelo desenvolvimento populacional, já que a Região Metropolitana do Recife, a sexta maior metrópole do Brasil, se tornou um importante centro econômico. Grandes mudanças de remodelamento de paisagens foram necessárias para a acomodar a população, muitas vezes de forma desorganizada, levando a devastação dos habitats naturais, e consequentemente, danos indiretos e diretos na conservação da fauna por meio da fragmentação das áreas. Um dos grandes exemplos é o domínio da Mata Atlântica, com seu clima quente e úmido (PEEL et al., 2007), proporcionando habitats adequados para populações de répteis e anfíbios, que teve sua fitofisionomia alterada e degradada em cerca de $8 \%$ da sua cobertura vegetal original (CUNHA et al., 2019), acarretando em modificações na estrutura, composição e abundância de espécies nos fragmentos remanescentes, que tendem a diminuir e isolarem-se cada vez mais (ABDALA, 2007, CASTRO, 2008), ocasionando um aumento na sobreposição de espaço entre homem e fauna.

Para mitigar os efeitos negativos das atividades humanas sobre a herpetofauna urbana, faz-se necessários trabalhos de fiscalização e manejo adequado dos animais. No estado de Pernambuco, até o ano de 2014, três eram as principais instituições que atuavam de forma direta com a fauna silvestre: $\mathrm{O}$ Instituto Brasileiro do Meio Ambiente e dos Recursos Naturais Renováveis (IBAMA); a Companhia Independente de Policiamento do Meio Ambiente (CIPOMA); o Grupamento de Bombeiros e Salvamento (Bombeiro). A conservação da fauna silvestre é de extrema importância para a estabilidade biológica e o equilíbrio ambiental, sendo o tráfico de animais silvestres, a introdução de espécies exóticas uma das grandes ameaças à biodiversidade (BRASIL, 2006; WWF, 2016; DESTRO, 2018). Por este motivo, o presente artigo objetivou elaborar um diagnóstico da herpetofauna resgatada, recebida e apreendida pelos órgãos de fauna de Pernambuco, no período de 2010 a 2014, avaliando a lista de espécies de modo quantitativo e qualitativo, com informações sobre o status de conservação das espécies, sua distribuição nos municípios de abrangência referente a sua procedência e posterior destinação, bem como, implicações ambientais em decorrência destas práticas.

\section{MATERIAIS E MÉTODOS}

\section{Área de estudo}

A área de enfoque do trabalho foi a Região Metropolitana do Recife (RMR), localizada na porção leste do estado de Pernambuco ( $35^{\circ} 15^{\prime} 49.60^{\prime \prime}-34^{\circ} 49^{\prime} 22.13^{\prime \prime} 0 ; 7^{\circ} 41^{\prime} 3.69^{\prime \prime}-8^{\circ} 36^{\prime} 14.98^{\prime \prime}$ ) ), com área territorial de aproximadamente $3.200 \mathrm{~km}^{2}$, composta por 14 municípios: Abreu e Lima, Araçoiaba, Cabo de Santo 
Agostinho, Camaragibe, Ilha de Itamaracá, Igarassu, Ipojuca, Itapissuma, Jaboatão dos Guararapes, Moreno, Olinda, Paulista, Recife e São Lourenço da Mata (Figura 1); sendo a maior região metropolitana do NorteNordeste do Brasil.

Localizado na Zona Intertropical, Pernambuco temperatura média em torno de $27^{\circ} \mathrm{C}$, que podem alterar de acordo com a variação das massas de ar e de relevo, predominando na RMR o clima tropical úmido, com chuvas no inverno e outono e, de acordo com o Serviço Geológico do Brasil (ASSIS et al., 2002), os totais anuais médios de precipitação variam de $2.000 \mathrm{~mm}$, nas regiões litorâneas, diminuindo com o afastamento do litoral até valores próximos a $1.200 \mathrm{~mm}$, na região oeste de São Lourenço da Mata, sendo os meses de maio, junho e julho com quase metade dos totais de precipitação anual, e outubro, novembro e dezembro o período mais seco, com apenas 7,5\% das chuvas totais (BRASIL, 2013).

A RMR possui uma vasta rede de rios e canais, formando uma extensa e ramificada malha fluvial e área de drenagem, que varia de volume de acordo com a intensidade das chuvas (CARVALHO, 2004; MASCARENHAS JUNIOR et al., 2018; GOUVEIA et al., 2019). Como principais rios, estão os rios Beberibe, Capibaribe, Tejipió, Moxotó, Jangadinha, Jiquiá e Jordão, além de diversas lagoas, canais e açudes.

A região é composta pela vegetação litorânea, marcada por alagados e manguezais, e remanescente de Mata Atlântica, que ocupa apenas 8\% da RMR (RAMALHO, 2014); onde a degradação ambiental continua em crescimento, principalmente em municípios que compõem a periferia da metrópole. Muito disto se dá a vertiginosa expansão do tecido urbano (SANTOS, 2013).

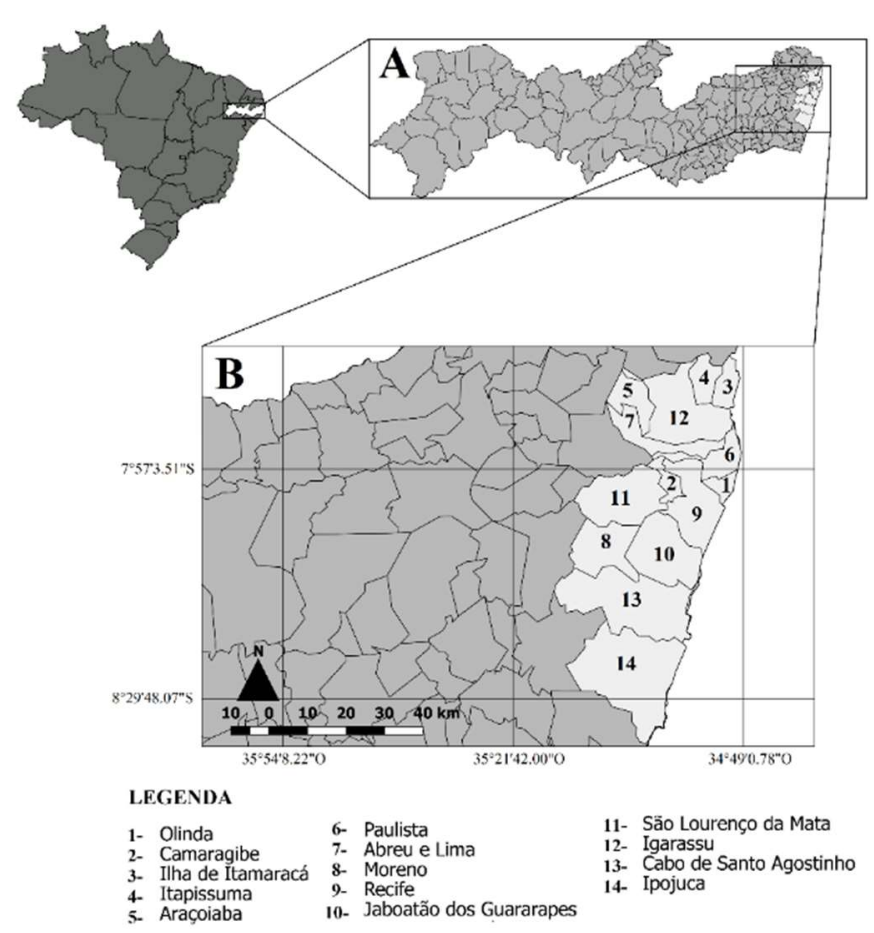

Figura 1: Localização da região Metropolitana do Recife (RMR), Pernambuco, com destaque, para os municípios de registros da herpetofauna resgatada, apreendida, recebida e destinada pelos órgãos de fauna de Pernambuco.

*A (Pernambuco); B (Região Metropolitana do Recife).

Segundo Oliveira et al. (2014), 44,68\% do território do Recife são áreas verdes, formada por diversos 
fragmentos de áreas incluídas na cidade, sendo 64\% das áreas dentro de Unidades de Conservação da Natureza (UCN): UCN Beberibe (LUOS - Lei Municipal 16.176/96 - Decreto 23.804/08), UCN Dois Irmãos (Lei Municipal 16.176/96 - Decreto 23.807/08) e UCN APA Mata da Várzea (LUOS 16.176/96 - Decreto 22.154/06); e os outros 36\% fragmentos distribuídos, como parques, praças, terrenos privados e outros.

\section{Procedimento metodológico}

Foram avaliados os boletins de ocorrências (B.O.) emitidos pelo CIPOMA (1ạ Companhia Independente de Policiamento do Meio Ambiente) e Bombeiro (Grupamento de Bombeiros de Salvamento - GBS) e os relatórios eletrônicos anuais do Centro de Triagem de Animais Silvestres (CETAS) do IBAMA, entre os anos de 2010 e 2014. Os dados foram tabulados com as informações de data da ocorrência, o endereço onde o animal foi encontrado, quem realizou a captura (instituição ou população), a espécie (ou nome genérico), o destino final dos animais, o responsável pela formulação do B.O. e demais observações, sendo neste campo, avaliada a forma de entrada do animal ou qualquer outra informação.

O levantamento dos dados apresentou lacunas nos anos de 2010 e 2011, com ausência dos registros do IBAMA e CIPOMA, respectivamente. No ano de 2014, as informações não estavam bem consolidadas apresentando lacunas, devido a transição da responsabilidade da gestão de fauna da esfera federal para estadual, em Pernambuco, saindo do IBAMA e indo para a Companhia Pernambucana de Controle da Poluição Ambiental e de Administração de Recursos Hídricos (CPRH) - Agência Estadual de Meio Ambiente, por meio da Instrução normativa ICMBIO/IBAMA no 01, de 08 de dezembro de 2014 (BRASIL, 2014).

Os animais foram classificados em Testudines, Crocodilianos e os animais pertencentes ao grupo Squamata: Serpentes, Lagartos (incluidos os representantes da infraordem Iguania e das famílias Teiidae e Lacertidae) e Anfisbenas. Os dados foram ordenados por grupo taxonômico para identificação das espécies, segundo Costa et al. (2015) e organizados de forma descritiva em tabelas e figuras construídas em planilha eletrônica.

O status de conservação das espécies foi baseado nas listas da União Internacional para Conservação da Natureza (IUCN, 2020), do Instituto Chico Mendes de Conservação e Biodiversidade (ICMbio, 2018), da Lista Estadual Oficial de Espécies da Fauna Ameaçadas de Extinção - Répteis emitida pelo Secretaria de Meio Ambiente e Sustentabilidade de Pernambuco - SEMAS (Resolução SEMAS № 1 DE 15/05/2017). Os táxons também foram avaliados na lista CITES (Convenção sobre o Comércio Internacional das Espécies da Fauna e da Flora Silvestres Ameaçadas de Extinção -, que tem como objetivo controlar e regulamentar o comércio de espécies de animais e plantas para garantir sua sobrevivência. O CITES criou uma lista de espécies, onde os animais e plantas foram categorizados, de acordo com a ameaça imposta a espécie pela exploração comercia, em: Apêndice I, que inclui espécies ameaçadas de extinção da qual só é permitido o comércio sob circunstâncias excepcionais; Apêndice II, que inclui as espécies não necessariamente ameaçadas de extinção cujo o comércio deve ser controlado para para evitar usos que empatem sua sobrevivência; Apêndice III, que 
Resgate, apreensão e destinação da herpetofauna pelos órgãos de fauna na região metropolitana do Recife, Pernambuco: contribuição para

engloba espécies protegidas em pelo menos um país e que tenha solicitado a CITES ajuda para o controle do comércio.

\section{Análise de dados}

A análise de dados constou de testes estatísticos realizados no software Biostats e todas as conclusões tomadas a nível de significância de $5 \%(p=0,05)$. Regressões lineares e testes de correlação de Pearson foram realizadas entre o número de registros mensal de cada grupo da herpetofauna e a média de pluviosidade mensal observada no período amostrado (janeiro de 2010 à dezembro de 2014).

Para relacionar à atividade sazonal (informações pluviométricas), serão utilizados os dados da Agência Pernambucana de Águas e Clima (APAC) e o número de animais resgatados mensalmente por espécies ou grupo taxonômico.

Para a distribuição espacial dos espécimes registrados nos B.Os, foram utilizados mapas concebidos através do software Google Earth Plus (CICCHI, 2007) para a identidicação das coordenadas geográficas a partir do endereço fornecido no B.O. e os mapas deste trabalho foram confeccionados a partir do software QGis.

\section{RESULTADOS}

Foram analisados 1.369 boletins de ocorrência do período de 2010 a 2014 (59,7\% Bombeiro, 27,9\% IBAMA, e 12,3\% CIPOMA), um total de 1.793 registros da herpetofauna, sendo 162 (2010), 493 (2011), 560 (2013) e 142 (2014), com identificação taxonômica em 1.345 e um percentual de 23,6\% sem informação de identificação (Tabela 1).

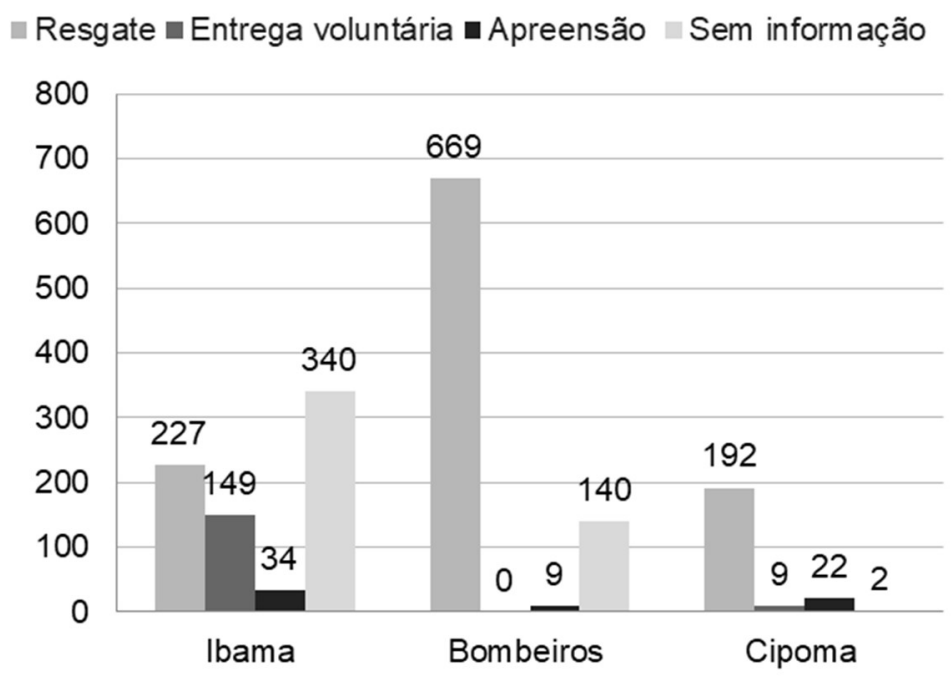

Figura 2: Número de registros da herpetofauna por tipo de ocorrência (apreensão, resgates e entregas voluntárias) realizadas em Pernambuco, pelo CIPOMA, IBAMA e Corpo de Bombeiros, no período de 2010 a 2014.

Em relação ao tipo de ocorrência, 60,7\% foram classificados como resgate, 8,8\% foram entregas voluntárias e 3,6\% apreensões, contudo, 26,9\% não apresentavam informações sobre o tipo de ocorrência. O Bombeiro, apresentou o maior número de resgates com $61,5 \%$ das ocorrências, apenas $13,8 \%$ das 
apreensões e nenhuma entrega voluntária. O IBAMA não apresentou registros nos anos de 2010 e 2014, todavia foi responsável por $94 \%$ do montante das entregas voluntárias, 52,3\% das apreensões e por 70,5\% das notificações que não apresentavam informações. O CIPOMA apresentou os menores números de registros, $17,6 \%$ de resgates, 5,7\% das entregas voluntárias e 33,4 \% das apreensões, além disso, não havia dados referentes ao ano de 2011 (Figura 2).

No tocante as apreensões, 50,8\% foram testudines, $29,2 \%$ serpentes, $12,3 \%$ jacarés e $7,7 \%$ lagartos. O grupo mais resgatado foi o das serpentes $(61 \%)$, seguindo por jacarés $(20 \%)$, testudines $(8,3 \%)$, lagartos $(9,6 \%)$ e anfisbenas $(0,1 \%)$. A entrega voluntária foi de $57 \%$ testudines, $3,8 \%$ jacarés, $13,3 \%$ lagartos e $25,9 \%$ serpentes.

No geral, de 2010 a 2014, foram registrados: $21,3 \%$ testudines, $16,2 \%$ de crocodilianos, 50,6\% serpentes, $11,6 \%$ lagartos e apenas $0,1 \%$ de anfisbenas. O Corpo de Bombeiros registrou 818 animais em B.Os., o IBAMA 750 animais em 382 B.O e o CIPOMA, apresentou os menores números, com 225 animais em 169 B.Os., analisados. As serpentes e jacarés foram os táxons que obtiveram maiores destaques (Figura 3).

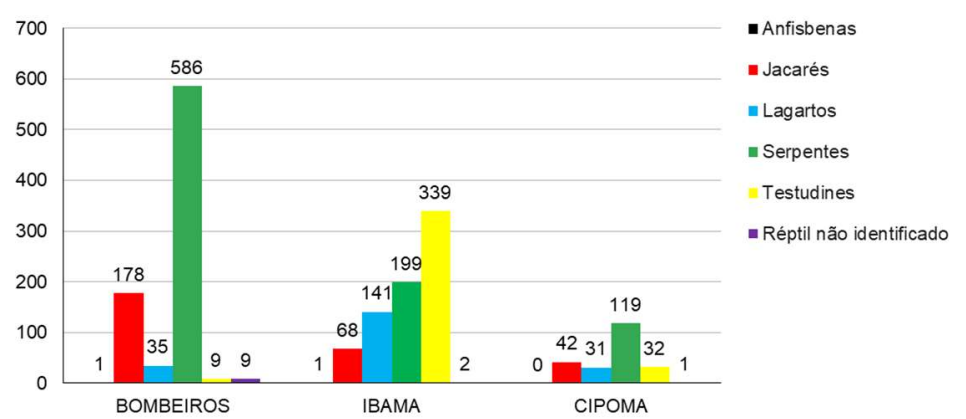

Figura 3: Números de contribuição dos grupos taxonômicos (Anfisbenas, Crocodilianos, Lagartos, Serpentes e Testudines) com maior número de espécies/espécimes recebidas, respectivamente, pelo Bombeiro, IBAMA e CIPOMA no período de 2010 a 2014.

A identificação taxonômica a nível específico ocorreu 76\% dos indivíduos, sendo identificados 24 táxons: Testudines (6 sp) pertencentes às famílias, Cheloniidae, Kinosternidae, Testudinidae, Chelidae e Podocnemididae; Crocodilianos (2 sp) da família Alligatoridae; Serpentes (13 sp) pertencentes às famílias Boidae, Columbridae, Elapidae, Viperidae e Xenodontinae; Lagartos ( $2 \mathrm{sp}$ ) pertencentes as famílias Iguanidae e Teiidae; e anfisbenas (1 sp) (Tabela 1).

As principais espécies registradas foram a Boa constrictor, Jiboia (77\%); Caiman latirostris, jacaré-depapo-amarelo (21,9\%); Chelonoidis sp., jabuti (13\%); Phrynops geoffroanus, cágado-de-barbicha (9\%) e Iguana iguana, Iguana (11\%).

Em relação ao status de conservação segundo IUCN, ICMBio e a Agência Estadual do Meio Ambiente (Lista de PE), 8,4\% das dos táxons estão enquadrados em alguma categoria de ameça mais grave. Segundo a IUCN, Eretmochelys imbricata é considerada criticamante em perigo (CR) e Podocnemis unifilis espécie endemica da região norte e exótica aqui no nordeste como vulnerável (VU). Quanto ao ICMBio e a Lista de répteis de Pernambuco, apenas uma espécie, E. Imbricata foi categorizada como em Perigo (EN). As 
serpentes e lagartos foram categorizados como pouco preocupante LC nas listas nacionais e regionais, com exceção da cobra do milho Pantherophis guttatus, por ser um animal exótico, não foi avaliado.

Tabela 1: Táxons da herpetofauna, por grupo taxonômico com registro de identificação, status de conservação das espécies e órgãos públicos responsáveis pela apreensão ou resgate, no estado de Pernambuco no período de 2010 a 2014.

\begin{tabular}{|c|c|c|c|c|c|c|c|c|c|c|c|c|c|c|c|c|c|c|c|c|c|c|}
\hline \multirow{2}{*}{ TÁXON } & \multicolumn{3}{|c|}{$\begin{array}{l}\text { STATUS DE } \\
\text { CONSERVAÇÃO }\end{array}$} & \multicolumn{3}{|c|}{ CITES } & \multicolumn{5}{|c|}{ IBAMA } & \multicolumn{5}{|c|}{ CIPOMA } & \multicolumn{5}{|c|}{ BOMBEIRO } & \multirow{2}{*}{$\begin{array}{l}\text { Núme } \\
\text { ro } \\
\text { Total } \\
\text { Ind. } \\
\end{array}$} \\
\hline & $\begin{array}{l}\text { IUC } \\
\mathrm{N}\end{array}$ & $\begin{array}{l}\text { ICMB } \\
\text { io }\end{array}$ & $\begin{array}{l}\text { List } \\
\text { a } \\
\text { PE }\end{array}$ & 1 & $\begin{array}{l}\text { I } \\
\text { I }\end{array}$ & $\begin{array}{l}\text { II } \\
\text { I }\end{array}$ & A & B & c & D & $\mathrm{E}$ & A & B & C & D & $\mathrm{E}$ & A & B & C & D & E & \\
\hline
\end{tabular}

TESTUDINES

Cheloniidae

Eretmochely

$s$ imbricata

$\begin{array}{lllllllllllllllllllllll}\text { (Linnaeus, } & \mathrm{CR} & \mathrm{EN} & \mathrm{EN} & \mathrm{x} & - & - & 0 & 1 & 1 & 0 & 0 & 0 & 0 & 0 & 0 & 0 & 0 & 0 & 0 & 0 & 0\end{array}$

1766)

Tartaruga-

de-pente

Kinosternida

e

Kinosternon

scorpioides

(Linnaeus,

1766)

Muçuã

Testudinidae

Chelonoidis

sp. - Jabuti

Chelidae

Mesoclemmy

$s$ tuberculata

(Lûderwaldt,

1926)

Cágado-do-

Nordeste

Phrynops

geoffroanus

(Schweigger,

1812)

Cágado-de-

barbicha

Podocnemidi

dae

Podocnemis

unifilis (Trosc

hel, 1848)**

- Tracajá

CROCODYLIA

Alligatoridae

Caiman

latirostris

(Daudin,

1802)

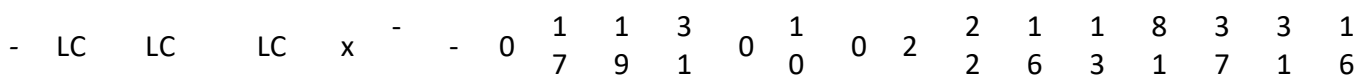

Jacaré-de-

papo-

amarelo

Paleosuchus

palpebrosus

(Cuvier, 
Resgate, apreensão e destinação da herpetofauna pelos órgãos de fauna na região metropolitana do Recife, Pernambuco: contribuição para conservaçãoítulo: subtítulo

1807)

Jacaré-anão

SQUAMATA

Amphisbaeni

Amphisbaen

a sp. - Cobra-

de-duas-

cabeças

Iguanidae

Iguana

iguana
(Linnaeus,

1758)

Iguana

Teiidae

Salvator

merianae

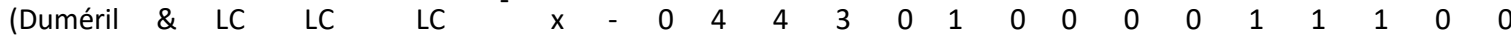

Bibron,

1839) - Teju

Boidae

Boa

$\begin{array}{llllllllllllllllllllllllll}\text { constrictor } & \\ \text { (Linnaeus, }\end{array}$

1758) - Jibóia

Epicrates

cenchria

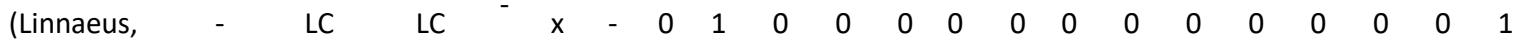

1758)

Salamanta

Colubridae

Chironius sp.

Oxybelis

LC LC LC $\quad-\quad-\quad-\quad \begin{array}{lllllllllllllllllllll} & 0 & 1 & 0 & 1 & 0 & 0 & 0 & 0 & 0 & 0 & 0 & 0 & 0 & 0 & 0 & 2\end{array}$

aeneus

(Wagler, LC LC LC $\quad-\quad-\quad-\quad \begin{array}{lllllllllllllllllllll} & \text { LC } & 0 & 0 & 0 & 0 & 0 & 0 & 0 & 0 & 0 & 0 & 2 & 0 & 1 & 0\end{array}$

1824)

Cobra-cipó

Philodryas

sp. - Cobra LC LC LC $\quad-\quad-\quad-\quad \begin{array}{lllllllllllllllllllllll} & 0 & 0 & 2 & 3 & 0 & 0 & 0 & 0 & 1 & 0 & 0 & 0 & 0 & 0 & 0\end{array}$ verde

Pantherophis

guttatus

(Linnaeus

1766) - Cobra

do milho

Sibynomorph

us neuwiedi

(Ihering,

1911)

LC LC

Dormideira

ou Papa-

lesma

Spilotes

pullatus

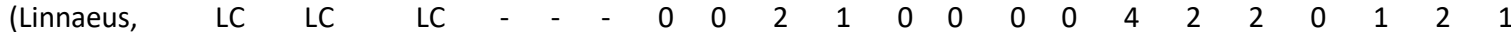

1758)

Caninana

Elapidae

$\begin{array}{llllllllllllllllllllllllllllll}\text { Micrurus sp. } & \text { LC } & \text { LC/D } & \text { DD } & - & - & - & 0 & 2 & 2 & 6 & 0 & 2 & 0 & 0 & 1 & 0 & 3 & 1 & 3 & 1 & 3 & 24\end{array}$

Revista Ibero-Americana de Ciências Ambientais 
Resgate, apreensão e destinação da herpetofauna pelos órgãos de fauna na região metropolitana do Recife, Pernambuco: contribuição para conservação

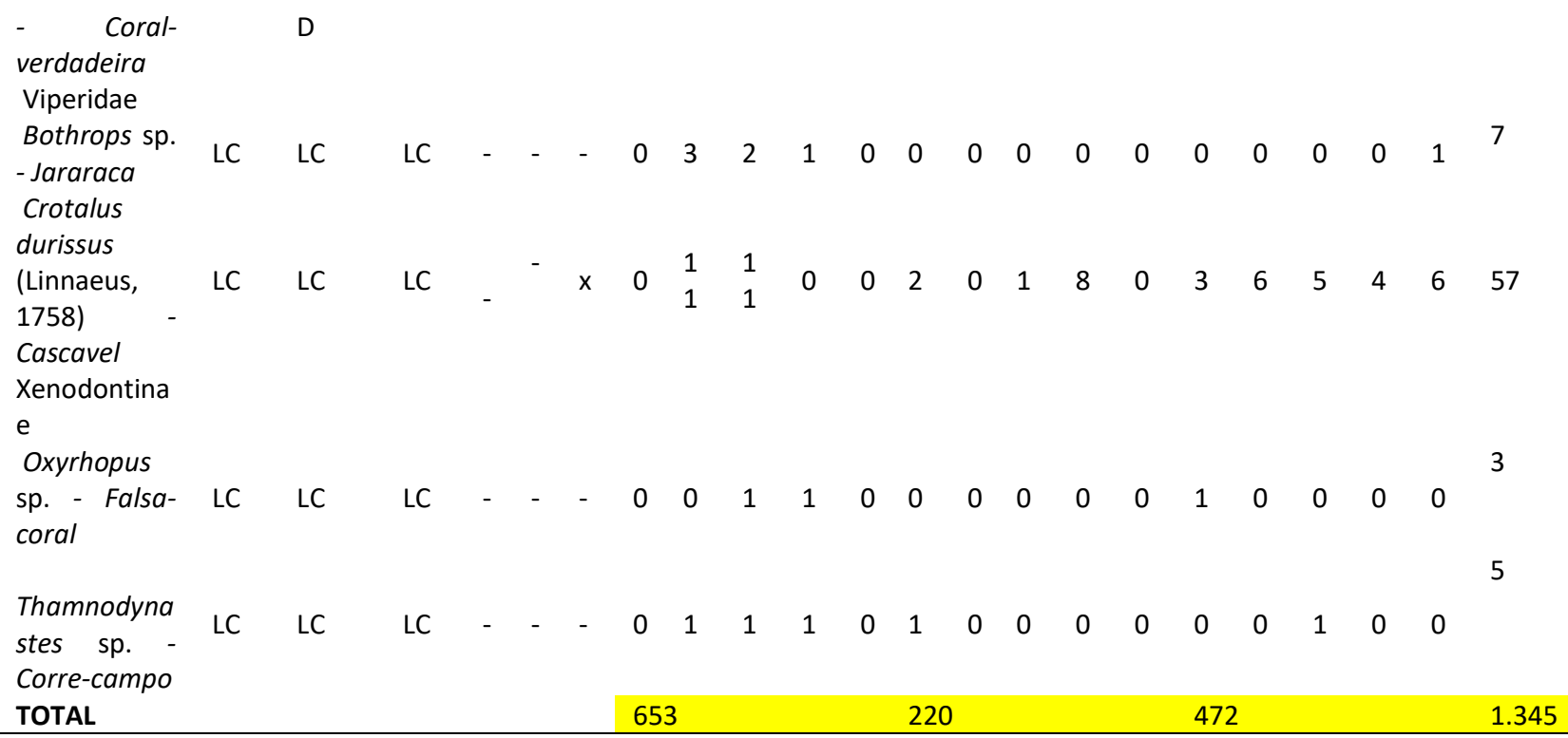

Status de Conservação: $\mathrm{LC}=$ menor preocupação; NT = quase ameaçada; VU = vulnerável; $\mathrm{DD}=$ Dados deficientes; $\mathrm{EN}=$ em perigo; CR - Criticamente em Perigo; “--“ = não consta. * A (ano 2010); B (ano 2011); C (ano 2012); D (ano 2013); E (ano 2014); ** espécie exótica para Pernambuco.

Nove espécies (37,5\%) estavam enquadradas nos apêndices da CITES. No apêndice I, foram registrados a $E$. Imbricata o $C$. latirostris. No apêndice II, foram encontradas dois testudines (Chelonoidis sp. e $P$. Unifilis), duas serpentes (B. constrictor e Epicrates cenchria) e dois lagartos (I. iguana e Salvator merianae). Já no apêndice III, foi registrada uma espécie de serpente (Crotalus durissus).

A procedência (local de origem do registro) não foi informada em 39,8\% dos B.O. e em 27,8\% não constava informações sobre a data de ocorrência. Os registros de herpetofauna resgatada e apreendidas ocorreram na maioria das cidades da RMR, 13 dos 14 municípios (excetuando-se em Araçoiaba), com maior quantitativo na capital e cidades vizinhas. O municipio de Recife apresentou o maior percetual de registros (24,1\%), seguindo por 7,8\% em Paulista, 5,6\% em Olinda, 4,1\% em Igarassu, 3,5\% em Abreu e Lima, 3,5\% em Camaragibe, 3,1\% em Jaboatão dos Guararapes, 1,6\% em Cabo de Santo Agostinho, 1,1\% na Ilha de Itamaracá, 0,7\% em Moreno, 0,6\% em Ipojuca e 0,3\% em Itapssuma; os outros 10\% estão relacionados a municípios fora da Região Metropolitana do Recife (Figura 4). Isso pode estar relacionado a grande quantidade de fragmentos de mata, o número de reservas e parques distribuídos pelos municípios, bem como, o maior adensamento de pessoas sobrepondo as áreas naturais (OLIVEIRA et al., 2014; GOUVEIA et al., 2019). Além disso, a urbanização pode ser um aspecto importante, já que Recife é o município com maior população no estado, e de modo complementar, a existencia de mercados e feiras livres onde ocorre o tráfico de animais, a exemplo do mercado da Madalena um local de destaque neste cenário ilegal, o local de 47,7\% das apreensões; o que potencializa as interações entre pessoas e a fauna urbana (DITCHKOFF et al., 2006; KISTLER et al., 2013; SOULSBURY et al., 2016). Seguido de Iputinga ( $n=35$ ) e Várzea ( $n=23$ ) no Recife; o bairro de Cruz de Rebouças ( $n=35$ ) em Igarassu, o bairro do Janga $(n=28)$ em Paulista, e o bairro de Prazeres ( $n=28$ ) em Jaboatão dos Guararapes; Em relação aos bairros com maiores registros de ocorrência, temos os bairros da Madalena ( $n=43$ ), sendo o Mercado da Madalena o local de 47,7\% das apreensões; Iputinga ( $n=$ 35) e Várzea ( $n=23$ ) no Recife; o bairro de Cruz de Rebouças ( $n=35)$ em Igarassu, o bairro do Janga ( $n=28)$ em Paulista, e o bairro de Prazeres $(n=28)$ em Jaboatão dos Guararapes. 

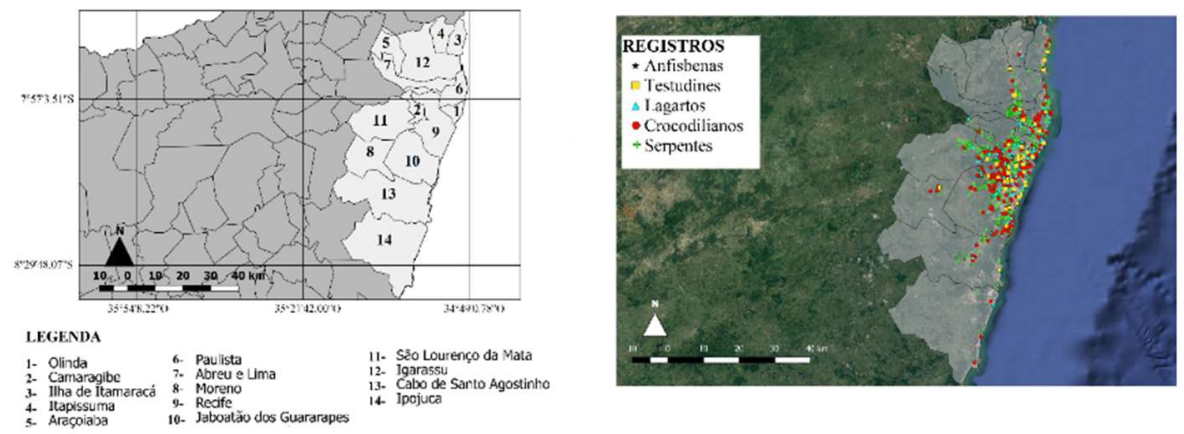

Figura 4: Distribuição dos registros da herpetofauna resgatada e apreendida pelos órgãos Bombeiro, IBAMA e CIPOMA no período de 2010 a 2014 na Região Metropolitana do Recife.

Quanto a destinação dos animais, apenas $12,3 \%$ das notificações apresentavam registro de soltura $(n=220)$, sendo identificados 19 pontos correspondendo a oito municípios e seis transferências para sede de outras instituições para a realização das solturas. Destes, 123 foram levados ao IBAMA para serem soltos, sem o registro do ponto de soltura. Ocorreu uma distribuição heterogênea nas áreas de soltura, co destaque para Recife com 43\%, Itamaracá e Jaboatão dos Guararapes com 15\%. Foram soltos 29 testudines, 40 crocodilianos e 143 squamata. As anfisbenas foram as únicas que não apresentaram nenhum registro de soltura (Figura 5).

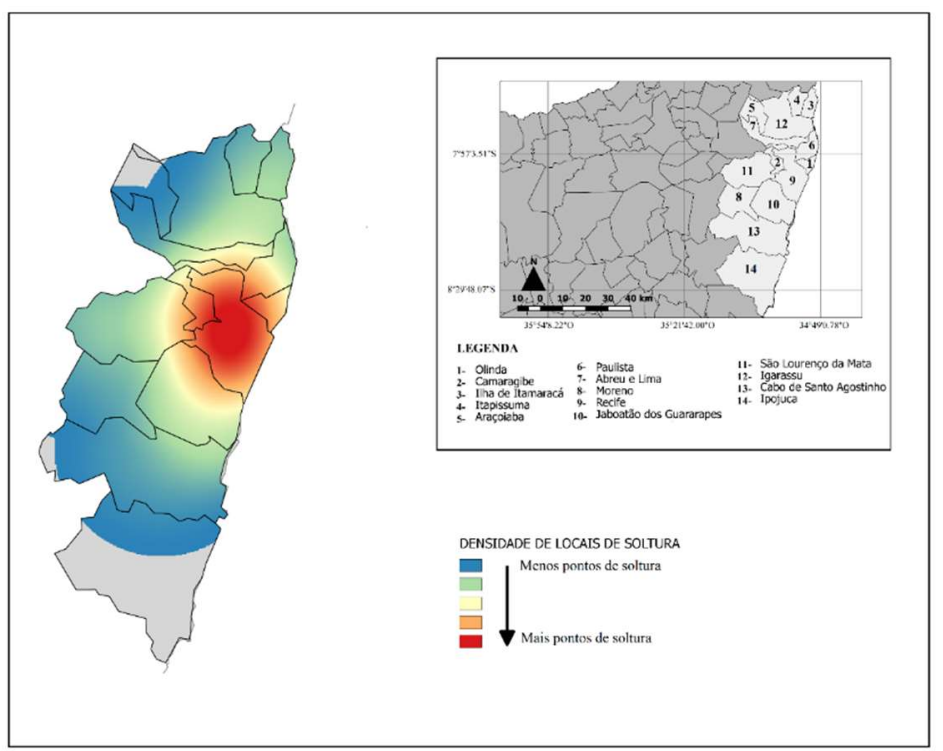

Figura 5: Densidade dos locais de soltura da herpetofauna resgatada e apreendida pelos órgãos Bombeiro, IBAMA e CIPOMA no período de 2010 a 2014 na Região Metropolitana do Recife.

A variação nos índices de pluviosidade apresentaram relação significativas com a variação no número de ocorrências apenas de serpentes $(R=0,26 ; p=0,04)$ e crocodilianos $(R=0,58 ; p=0,01)$. Por outro lado, a variação dos períodos chuvosos não apresentaram relação significativa com os registros de lagartos e testudines ( $R=0,02 ; p=0,72$ e $R=0,15 ; p=0,24$, respectivamente) (Figura 6 ). 


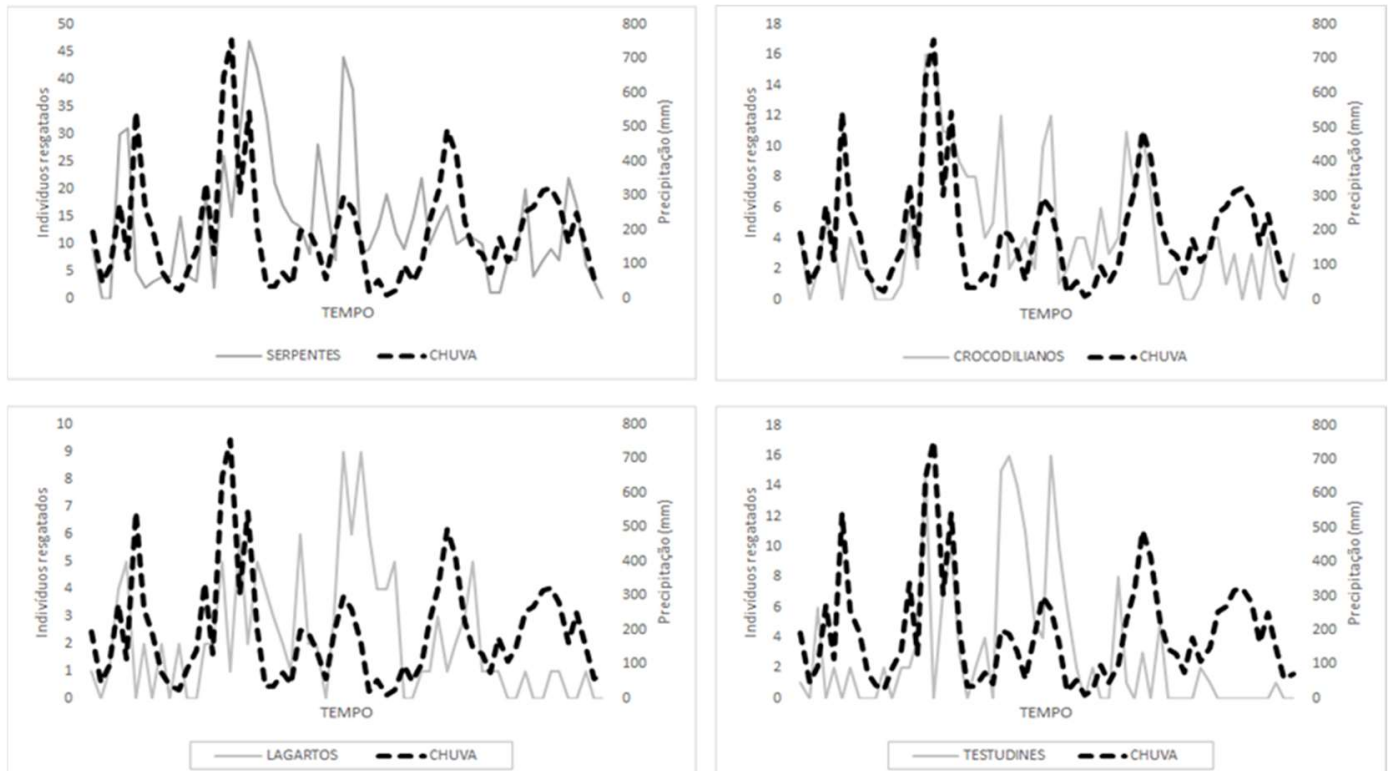

Figura 6: Relação dos índices pluviométricos mensais com os registros de herpetofauna registrada (excetuando-se anfisbenas) por Bombeiro, IBAMA e CIPOMA entre os anos de 2010 e 2014.

\section{DISCUSSÃO}

Os registros de herpetofauna resgatada e apreendidas ocorreram na maioria das cidades da RMR, com maior quantitativo na capital e cidades vizinhas. Isso pode estar relacionado a grande quantidade de fragmentos de mata, o número de reservas e parques distribuídos pelos municípios, bem como, o maior adensamento de pessoas sobrepondo as áreas naturais (OLIVEIRA et al., 2014; GOUVEIA et al., 2019). Além disso, a urbanização pode ser um aspecto importante, já que Recife é o município com maior população no estado, e de modo complementar, a existencia de mercados e feiras livres onde ocorre o tráfico de animais, a exemplo do mercado da Madalena um local de destaque neste cenário ilegal, potencializa as interações entre pessoas e a fauna urbana (DITCHKOFF et al., 2006; KISTLER et al., 2013, SOULSBURY et al., 2016).

Fatores ambientais relacionados a paisagem e clima contribuem para uma maior interação entre pessoas com a fauna. A vasta malha hídrica da região pode proporcionar hábitats ideais para espécies semiaquáticas, como crocodilianos e testudines dulcícolas (VERDADE, 1995; ANDRADE, 2009; BERNARDE, 2012; TEIXEIRA et al., 2015; FRENCH et al., 2018). A variação na pluviosidade local afeta direramente o regime hídrico (CARVALHO, 2004; MASCARENHAS JUNIOR et al., 2018; GOUVEIA et al., 2019), influenciando também na fauna associada. Além disso, o mosaíco natural que faz parte da malha urbana, com a presença de fragmentos florestais, rios e areas alagadas, proporciona a ocupação de novos nichos pela fauna. Várias espécies se beneficiam dos ambientes antropizados e utilizam as áreas urbanas em busca de recursos (FRENCH et al., 2018). Essa ocupação e adaptação cada vez maior da fauna em ambientes urbanizados, principalmente devido à fragmentação dos hábitats naturais, tem proporcionado o aumento nos encontros de animais em locais ocupados pelo ser humano (BEZERRA, 2006; BRUN et al., 2007; BRASIL, 2013). No entanto, outros organismos mais sensíveis estão cada vez mais isolados e ocasionalmente são registrados pela população, como é o caso do $P$. palpebrosus (CORREIA et al, 2019).

Em relação ao total de táxons identificados por grupo, os valores são superiores ou similares ao 
encontrado por Alves (2011) na Paraíba, que registrou 86\% de Squamata e $9 \%$ de crocodilianos. Também, Pinto (2015) registrou por meio de dados do CETAS da Bahia nos anos de 2012 a 2015, 72,3\% de Squamata, $7 \%$ de testudines e $1,3 \%$ de crocodilianos, sendo o único trabalho que registrou anfisbenas, com $0,2 \%$. É possível observar, de forma crescente, um aumento no número de registros em relação a crocodilianos, testudines e Squamata no nordeste do Brasil. Estudos realizados em outras regiões colocam os testudines como os mais resgatados, como em Goiás (COUTINHO et al., 2005; BASTOS et al., 2008) e Minas Gerais, onde Freitas et al. (2015) registraram no CETAS de Minas Gerais no ano de 2011 66,3\% de Squamata, 33\% testudines e $0,7 \%$ de crocodilianos. Bastos et al. (2008) registraram um maior quantitativo de apreensões de testudines trazidos ao CETAS de Goiás, concordando com informações do IBAMA, que registrou mais de 1.300 entradas nos CETAS oriundos de criação ilegal no Brasil no ano de 2014.

O maior quantitativo de resgates de crocodilianos aconteceu no segundo trimestre, no período de maior intensidade pluviométrica na região. O aumento das chuvas resulta na formação de alagados temporários e gera a inundações de canais e esgotos nos centros urbanos. A RMR apresenta muitas áreas de drenagem e extensa malha fluvial, permitindo os jacarés acessarem as áreas urbanizadas e encontros ocasionais com a população (MASCARENHAS JUNIOR et al., 2018). Além disso, as movimentações podem estar relacionadas a reprodução e ao territorialismo (LUZ, 2012), o que intensifica as chances de aparecimento desses animais em contextos mais antropizados (COUTINHO et al., 2005).

As apreensões e entregas voluntárias de lagartos podem estar relacionadas ao interesse desses animais como pets, a exemplo da I. Iguana, espécie mais vendidas no mercado internacional dentre os lagartos (RENCTAS, 2001; ANDRADE, 2009). A entrega voluntária foi uma ação positiva no orgão estadual através de campanhas educativas. Por serem encontrados em áreas de transição rural-urbana (GUMIERCOSTA et al., 2009; CABRAL, 2019), podem buscar refúgio em abrigos antropizados, o que também pode explicar o número de resgates ser maior que os outros grupos.

A relação significativa das variações pluviométricas e os registros de serpentes corrobora com Bernarde et al. (2014) e de Borges et al. (1999). O aumento das chuvas pode influenciar a dispersão desses animais das áreas alagadas para áreas secas (WALDEZ et al., 2009; SANTOS, 1995), muito comum em espécies fossoriais ou subfossoriais quando seus túneis inundam (FRAGA et al., 2013), [e.g.: a Micrurus sp. (MELGAREJO-GIMÉNEZ, 2002)]. Além disso, a termorregulação também pode estar relacionada ao número de resgates, por serem animais que são comumente encontrados regulando a temperatura corporal através do calor emitido pelo asfalto após chuvas (CARVALHO, 2014; RAMOS-ABRANTES et al., 2017; CARMO et al., 2018). Carmo et al. (2018) afirmaram que jibóias buscam locais asfaltados para termorregular, apesar de seu hábito arborícola. Isto pode potencializar os encontros com a espécie, como observado pelo grande quantitativo de registros neste trabalho.

Apenas dois indivíduos de anfisbenas foram resgatados e destes apenas um possuía informações de procedência. Esse número baixo de casos pode ser explicado pelo comportamento fossorial do grupo 
(NAVEGA-GONÇALVES et al., 2013), saindo de seus túneis devido alagamento de suas galerias nos períodos de chuva (NAVEGA-GONÇALVES, 2004). Em muitos casos, as anfisbenas são confundidas com serpentes e acabam sendo lesionadas, mortas pela população ou até registradas de formas errôneas nos boletins de ocorrências da corporações de fauna (NAVEGA-GONÇALVES, 2004; RIBEIRO, 2017; AMARAL, 2019; NAVEGAGONÇALVES et al., 2019).

Os B.Os. apresentaram variação de valores ao longos dos anos e discrepância nos dados por órgão de fauna, como a diferença no quantitativo de registros do GBS para o IBAMA (respectivamente, 818 e 225 notificações). Isso pode ser causado pela intensidade das fiscalizações e resgates, de acordo com a carência de recursos e de planejamento de operações de cada órgão (BASTOS et al., 2008). A falta de algumas informações nas notificações, como procedencia, identificação do táxon e local de soltura evidencia a necessidade de uma maior estruturação das instituições de fauna e treinamento do seus quadro de apoio nesses momentos de registro.

Nota-se também a necessidade de esforços de instituições de pesquisa para auxiliar os órgãos de fauna no monitoramento e elaboração de protocolos de captura e de soltura. De um modo geral, a falta de estudos sobre capacidade suporte das áreas naturais para fauna, dificulta uma avaliação e um direcionamento mais confiável quanto a um melhor local de soltura, de modo que as perturbações no ambiente sejam mitigadas, já que uma boa parte dos animais resgatados são consideradas espécies-chaves para manutenção do ecossistema (BORNATOWSKI, 2014; ODUM et al., 2017). Nota-se também a necessidade de esforços de instituições de pesquisa para auxiliar os órgãos de fauna no monitoramento e elaboração de protocolos de captura e de soltura, além de locais adequados para liberação, de modo que as perturbações no ambiente sejam mitigadas, já que uma boa parte dos animais resgatados são consideradas espécieschaves para manutenção do ecossistema (BORNATOWSKI, 2014; ODUM et al., 2017).

\section{CONCLUSÕES}

O diagnóstico da herpetofauna resgatada, recebida e apreendida pelos órgãos de fauna de Pernambuco, no período de 2010 a 2014, permitiu elaborar uma lista de espécies de modo quantitativo e qualitativo, com informaç̧̃es sobre o status de conservação das espécies, sua distribuição nos municípios de abrangência referente a sua procedência e posterior destinação, bem como, implicações ambientais em decorrência destas práticas.

Os testudines são os que mais foram apreendidos possivelmente devido ao tráfico e a criação como pets. As serpentes apresentaram maiores números na época de seus períodos reprodutivos, também mostrando um aumento de acordo o aumento da precipitação, provavelmente devido a inundações em seu ambiente natural. Os crocodilianos também apresentaram maiores números de acordo com o aumento da precipitação, contudo por motivos opostos as serpentes, já que de maneira geral possuem uma afinidade maior com a água e com a grande quantidade de malhas hídricas na RMR, que aumentam de acordo com as precipitações no peíodo de abril a julho e abrem novas rotas de dispersão para os jacarés. 
Quanto ao status de conservação, apenas duas das epécies encontradas foram classificadas em algum nível de ameaça grave, sendo os testudines Eretmochelys imbricata e Podocnemis unifilis.

Em relação à destinação, o animal silvestre tem seu papel ecológico sustentando a biodiversidade, $\mathrm{e}$ a eficiência de solturas em áreas sem a fiscalização é falha, já que a caça e a degradação de áreas verdes é cada vez maior. Concluindo que centenas de animais são devolvidos à natureza aleatoriamente, gerando, a longo prazo, grandes prejuízos à conservação da fauna. Recomenda-se a fiscalização e notificação das solturas em áreas estudadas previamente para a não haver danos a fauna já estabelecida no local, além de regular o número de indivíduos soltos, sendo o acompanhamento dos locais de soltura de extrema importância ecológica.

A falta de dados de alguns órgãos de fauna comprometeu a padronização dos dados e as discrepâncias nos números de ações foram por questões internas financeiras e administrativas. Há urgência na informatização dessas informações para direcionar esforços mais eficiente de monitoramento relacionadas ao resgate e apreenção e áreas de soltura. Essas informações são úteis na elaboração de ações de caráter educativo-ambiental, tanto para o combate do tráfico, quanto para conscientização da população em relação a conservação desse grupo tão importante, onde deve-se orientar entrar em contato com os órgãos responsáveis se ocorrerem encontros ocasionais com a herpetofauna urbana.

\section{REFERÊNCIAS}

ABDALA, A. V. D.. A proteção da fauna e o tráfico de animais silvestres. Dissertação (Mestrado em Direito) Universidade Metodista de Piracicaba, São Paulo, 2007.

ALVES, I. B. S.. Diversidade do resgate de fauna e as ações do 3 Batalhão de Bombeiros Militar da Paraíba em Guarabira-PB. Monografia (Bacharelado em Ciências Biológicas) - Universidade Estadual da Paraíba, Campina Grande, 2011.

AMARAL, J. M. S.. “O incrível mundo dos anfíbios e répteis da Mata Atlântica" ações educativas no entorno de unidades de conservação. Monografia (Bacharelado em Ciências Biológicas) - Universidade Federal Rural de Pernambuco, Recife, 2019.

ANDRADE, C. A. F.. Bicho da vez: Iguana-Verde (Iguana iguana). 2009.

ASSIS, H. M. B.; ASSUNÇÃO, P. R. S. D.; PFALTZGRAFF, P. A. D. S.; MIRANDA, J. L. F. D.; ARRAES, C. E. D. S.; GUERRA, S. M. S.; COSTA FILHO, D.. Sistema de informações para gestão territorial da região metropolitana do Recife. 2002.

BASTOS, L. F.; LUZ, V. L. F.; REIS, I. J.; SOUZA, V. L.. Apreensão de espécimes da fauna silvestre em Goiás - situação e destinação. Rev. Bio. Neotrop., v.5, n.2, p.51-63, 2008. DOI: https://doi.org/10.5216/rbn.v5i2.9822

BERNARDE, P. S.. Anfíbios e répteis: Introdução ao Estudo da Herpetofauna Brasileira. Anolis Books, 2012.
BERNARDE, P. S.; GOMES, J. O.. Serpentes peçonhentas e ofidismo em Cruzeiro do Sul, Alto Juruá, Estado do Acre, Brasil. 2014. In: SIMPÓSIO MINEIRO DE GEOGRAFIA. Anais. DOI: https://doi.org/10.1590/S0044-59672012000100008

BEZERRA, M. G. C. L.. Transformações espaço-temporais de mata de Dois Irmãos a partir dos processos de apropriação do espaço. Dissertação (Mestrado em Geografia) Universidade Federal de Pernambuco, Recife, 2006.

BORGES, C. C.; SADAHIRO, M.; SANTOS, M. C.. Aspectos epidemiológicos e clínicos dos acidentes ofídicos ocorridos nos municípios do Estado do Amazonas. Revista da Sociedade Brasileira de Medicina Tropical, v.32, p.637-646, 1999. DOI: https://doi.org/10.1590/S0037$\underline{86821999000600005}$

BORNATOWSKI, H.. Importância ecológica dos tubarões e raias em uma rede trófica na Costa Sul do Brasil. Tese (Doutourado em Zoologia) - Universidade Federal do Paraná, Curitiba, 2014.

BUJES, C. S.. Os Testudines continentais do Rio Grande do Sul, Brasil: taxonomia, história natural e conservação. Iheringia, Série Zoologia, v.100, n.4, p.413-424, 2010. DOI: https://doi.org/10.1590/S0073-47212010000400016

BRUN, F. G. K.; LINK, D.; BRUN, E. J.. O emprego da arborização na manutenção da biodiversidade de fauna em áreas urbanas. Revista da Sociedade Brasileira de Arborização Urbana, v.2, n.1, p.117-127, 2007. DOI: https://doi.org/10.5380/revsbau.v2i1.66253 
BRASIL. Lista estadual de répteis ameaçados tem 22 espécies. Recife: $\mathrm{CPRH}, 2014$.

BRASIL. Sistema de informações geoambientais da Região Metropolitana do Recife. Programa de Gestão Territorial. Recife: CPRM, 2003.

BRASIL. Secretaria do Meio Ambiente. Fauna urbana. Governo do Estado de São Paulo. Educação Ambiental, 2013.

BRASIL. Ministério do Meio Ambiente. PROBIO Educação Ambiental. Brasília: Departamento de Ecologia da Universidade de Brasília/MMA, 2006.

CABRAL, S. O.. Dieta de lagartos e serpentes atropelados em rodovias do semiárido nordestino no estado do Rio Grande do Norte, RN. Dissertação (Mestrado em Ciência Animal) - Universidade Federal Rural do Semi-árido, Mossoró, 2019.

CARVALHO, L. E. P.. Os descaminhos das águas no Recife: os canais, os moradores e a gestão. Dissertação (Mestrado em Geografia) - Universidade Federal de Pernambuco, Pernambuco, 2004.

CARVALHO, C. F.. Atropelamento de vertebrados, hotspots de atropelamentos e parâmetros associados, BR-050, trecho Uberlândia-Uberaba. Dissertação (Mestrado em Ecologia) - Universidade Federal de Uberlândia, Uberlândia, 2014.

CARREIRA, L. B. T.; SABBAG, O. J.; ABE, A. S.. Viabilidade econômica da criação de matrizes e reprodutores de Caiman latirostris no estado de São Paulo. Boletim do Instituto de Pesca, v.41, n.3, p.687-695, 2018.

CASTRO, D.. Efeitos de Borda em ecossistemas tropicais: síntese bibliográfica e estudo de caso em fragmentos de cerrado, na região nordeste do estado de São Paulo. Dissertação (Mestrado em Ecologia) - Universidade de São Paulo, São Paulo, 2008.

CARMO, C. C.; LOPES, C. E. B.; ALVES, P. V.; SCHWINDEN, G. $M$.. Atropelamento de serpente Boa constrictor: ameaça à manutenção do ambiente selvagem no campus do Itaperi. Ci. Anim., p.89-98, 2018.

$\mathrm{CICCHI,} \mathrm{P.} \mathrm{J.} \mathrm{P..} \mathrm{Dados} \mathrm{ecológicos} \mathrm{da} \mathrm{herpetofauna} \mathrm{do}$ Parque Estadual da Ilha Anchieta, Ubatuba, São Paulo, Brasil - Botucatu. Dissertação (Mestrado em Zoologia) Universidade Estadual Paulista, São Paulo, 2007.

COUTINHO, M. E.; CAMPOS, Z. M. S.; CARDOSO, F.; MARTINELLI, P.; CASTRO, A.. Ciclo reprodutivo de machos e fêmeas de jacaré-do-Pantanal, Caiman crocodilus yacare. Embrapa Pantanal - Comunicado Técnico (INFOTECA-E), 2005.

COSTA, H. C.; BÉRNILS, R. S..Répteis do Brasil e suas Unidades Federativas: Lista de espécies. Herpetologia Brasileira, v.8, n.1, p.11-57, 2018. DOI: http://dx.doi.org/10.1590/0103-8478cr20131212

COSTA, H. C.; BÉRNILS, R. S.. Répteis brasileiros: lista de espécies 2015. Herpetologia Brasileira, v.4, n.3, p.75-93,
2015.

CUNHA, A. M.; FONTES, M. P. F.; LANI, J. L. Mineralogical and chemical attributes of soils from the Brazilian Atlantic Forest domain. Scientia Agricola, v.76, n.1, p.82-92, 2019. DOI: https://doi.org/10.1590/1678-992x-2017-0109

DESTRO, G. F. G.. Tráfico de Animais Silvestres: Da captura ao retorno à natureza. Tese (Doutorado em Ecologia e Evolução) - Universidade Federal de Goiás, Goiânia, 2018.

DITCHKOFF, S. S.; SAALFELD, S. T.; GIBSON, C. J.. Animal behavior in urban ecosystems: modifications due to humaninduced stress. Urban Ecosystems, v.9, n.1, p.5-12, 2006. DOI: https://doi.org/10.1007/s11252-006-3262-3

FRAGA, F.; LIMA, A. P.; PRUDENTE, A. D. C.; MAGNUSSON, W. E.. Guide to the snakes of the Manaus region: Central Amazonia. Manaus: Inpa, 2013.

FREITAS, A. C. P.; OVIEDO-PASTRANA, M. E.; VILELA, D. A. R.; PEREIRA, P. L. L.; LOUREIRO, L. D. O. C.; HADDAD, J. P. A.; SOARES, D. F. M.. Diagnóstico de animais ilegais recebidos no centro de triagem de animais silvestres de Belo Horizonte, Estado de Minas Gerais, no ano de 2011. Ciência Rural, Santa Maria, v.45, n.1, p.163-170, 2015. DOI: https://doi.org/10.1590/0103-8478cr20131212

FRENCH, S. S.; WEBB, A. C.; HUDSON, S. B.; VIRGIN, E. E.. Town and Country Reptiles: A Review of Reptilian Responses to Urbanization. Integrative and Comparative Biology, v.58, p.948-966, n.5, 2018. DOI:

https://doi.org/10.1093/icb/icy052

GOUVEIA, R. L.; SELVA, V. S. F.. Educação ambiental para a revitalização de rios em áreas urbanas. Educação Ambiental em Ação, v.68, 2019.

GUMIER-COSTA, F.; SPERBER, C. F.. Atropelamentos de vertebrados na Floresta Nacional de Carajás, Pará, Brasil. Acta Amazônica, v.39, n.2, p.459-466, 2009. DOI: https://doi.org/10.1590/S0044-59672009000200027

ICMBio. Instituto Chico Mendes de Conservação da Biodiversidade. 2018. Livro Vermelho da Fauna Brasileira Ameaçada de Extinção: Volume IV - Répteis. In: Livro Vermelho da Fauna Brasileira Ameaçada de Extinção. Brasília: ICMBio. p.252.

IUCN. União Internacional para Conservação da Natureza. The IUCN Red List of Threatened Species. IUCN, 2020.

KISTLER, C.; HEGGLIN, D.; VON WATTENWYL, K.; BONTADINA, F.. Is electric fencing an efficient and animalfriendly tool to prevent stone martens from entering buildings?. European Journal of Wildlife Research, v.59, n.6, p.905-909, 2013. DOI: https://doi.org/10.1007/s10344-013$\underline{0752-5}$

KUHNEN, V. V.; KANAAN, V. T.. Wildlife trade in Brazil: A closer look at wild pets welfare issues. Braz. J. Biol., v.74, n.1, p.124-127, 2014. DOI: https://doi.org/10.1590/1519$\underline{6984.18912}$

LOPES, J. C. A.. Operações de fiscalização da fauna: análise, procedimentos e resultados. ANIMAIS silvestres: vida à 
venda, 2002.

LUCHESE, M. S.. A herpetologia no ensino fundamental: o que os alunos pensam e aprendem. Monografia (Licenciatura em Biologia) - Universidade Federal do Rio Grande do Sul, Porto Alegre, 2013.

LUZ, C.. Conservação de Caiman latirostris (Daudin, 1801): interações entre pescadores e o Jacaré-de-papo-amarelo na comunidade Barra do João Pedro, no município de Maquiné, RS. Tese (Especialização em Diversidade e Conservação de Fauna) - Universidade Federal do Rio Grande do Sul, Porto Alegre, 2012.

MARQUES, M. S.. Estudo comportamental de Caiman yacare (Jacaré-do-Pantanal) in situ e ex situ. Rev. Cient. Faminas, v.3, p.11-20, 2007.

MASCARENHAS JÚNIOR, P. B.; SANTOS, E. M.; CORREIA, J. M. S.. Diagnóstico dos Resgates de Jacarés na Região Metropolitana do Recife, Pernambuco. Rev. IberoAmericana de Ciências Ambientais, v.9, n.4, 2018. DOI: https://doi.org/10.6008/CBPC2179-6858.2018.004.0011

MARTINS, M.; MOLINA, F. B.. Panorama geral dos répteis ameaçados do Brasil. In: Livro vermelho da Fauna Brasileira ameaçada de extinção (ABM Machado, GM Drummond, AP Paglia). Brasília: MMA, 2008.

MELGAREJO-GIMÉNEZ, A. R.. Criação e manejo de serpentes. In: ANDRADE, A.; PINTO, S. C.; OLIVEIRA, R. S.. Animais de laboratório: criação e experimentação. Rio de Janeiro: Fiocruz, 2002. p.175-199.

MOURA, M. R.; MOTTA, A. P.; FERNANDES, V. D.; FEIO, R. N. Herpetofauna da Serra do Brigadeiro, um remanescente de Mata Atlântica em Minas Gerais, sudeste do Brasil. Biota Neotropica, v.12, n.1, p.209-235, 2012. DOI: https://doi.org/10.1590/S1676-06032012000100017

NASSARO, M. R. F.. Polícia Militar Ambiental do Estado de São Paulo: Chefe da Divisão de Operações Policiais da Polícia Militar Ambiental do Estado de São Paulo, Brazil. Dummy Cover, 2001.

NAVEGA-GONÇALVES, M. E. C.. Anfisbenas: quem são essas desconhecidas?. Ciência Hoje, 2004.

NAVEGA-GONÇALVES, M. E. C.; SILVA, J. R.. Respiratory system of Amphisbaena vermicularis and Amphisbaena microcephala (Squamata, Amphisbaenia, Amphisbaenidae). Iheringia, Série Zoologia, v.103, n.1, p.20-30, 2013. DOI: https://doi.org/10.1590/S0073-47212013000100003

NAVEGA-GONÇALVES, M. E. C.; ALMEIDA-BENITES, J. P.. Amphisbaenia: Adaptações para o Modo de Vida Fossorial. Revista Brasileira de Zoociências, v.20, n.2, p.1-30, 2019. DOI: https://doi.org/10.34019/2596-3325.2019.v20.26103

ODUM, E. P.; BARRET, G. W.. Fundamentos de Ecologia. São Paulo: Cengage Learning, 2017.

OLIVEIRA, T. D.; DANTAS, J. G.; BOTLER, M.; SILVA, R. D.; SILVA, J. D.; NEVES, T. D. F.. Mensuração e distribuição do verde urbano no município do Recife-PE: bases para a gestão ambiental urbana. 2014.

PAGANO, I. S. A.; SOUSA, A. E. A. B.; WAGNER, P. G. C.; RAMOS, R. T. C.. Aves depositadas no Centro de Triagem de Animais Silvestres do IBAMA na Paraíba: uma amostra do tráfico de aves silvestres no estado. Rev. CEMAVE, v.3, n.2, 2009.

PEEL, M. C.; FINLAYSON, B. L.; MCMAHON, T. A.. Updated world map of the Köppen-Geiger climate classification. Hydrology and Earth System Sciences Discussions, v.4, p.439-473, 2007. DOI: https://doi.org/10.5194/hess-111633-2007

PETTER, C. A. B.. Tráfico de animais silvestres. 2013.

PINTO, C. M.; TOREZANI, J.; PIGOZZO, C. M.. Situação do resgate de fauna para o Centro de Triagem de Animais Silvestres (CETAS) de Salvador/BA. 2015.

POUGH, H.; JANIS, C. M.; HEISER, J. B.. A vida dos vertebrados. 4 ed. São Paulo: Atheneu, 2008.

RAMALHO, P. A. A. M.. Desmatamento da mata atlântica em Pernambuco: uma análise sobre a aplicabilidade da legislação ambiental. 2014.

RAMOS-ABRANTES, M. M.; CARREIRO, A. N.; ARAÚJO, D. V. F.; SOUZA, J. G.; LIMA, J. P. R.; CEZAR, H. R. A.; ABRANTES, S. H. F.. Vertebrados silvestres atropelados na rodovia BR-230, Paraíba, Brasil. Pubvet, v.12, p.139, 2017. DOI: https://doi.org/10.22256/pubvet.v12n1a5.1-7

RENCTAS. Rede Nacional Contra o Tráfico de Animais Silvestres. 10 Relatório Nacional sobre o tráfico de fauna silvestre. 2001.

RIBEIRO, M. G.. Imaginário da serpente de A a Z. Campina Grande: EDUEPB, 2017.

RODRIGUES, L. L.. Frugivoria e dispersão de sementes pelo Jabuti-Piranga Chelonoidis carbonaria. 2016. DOI: https://doi.org/10.13140/RG.2.2.32602.24007

SANTOS, O.. A região metropolitana do Recife e os desafios do planejamento urbano frente à crise ambiental contemporânea. Revista OKARA: Geografia em debate, v.8, n.1, p.179-194, 2013.

SANTOS, V. M.. Diagnóstico da fauna silvestre recebida no Centro de Triagem de Animais Silvestres de AlagoasCETAS/IBAMA/AL. In: CONGRESSO DE ECOLOGIA DO BRASIL. Anais. 2009.

SANTOS, A. C.. Serpentes de Interesse Médico da Amazônia: Biologia, Venenos e Tratamento de Acidentes. Manaus: UA/SESU, 1995.

SOMAWEERA, R.; NIFONG, J.; ROSENBLATT, A.; BRIEN, M.L.; COMBRINK, X.; ELSEY, R. M.; GRIGG, G.; MAGNUSSON, W. E.; MAZZOTTI, F. J.; PEARCY, A.; PLATT, S. G.; SHIRLEY, M. H.; TELLEZ, M.; PLOEG, J. V. D.; WEBB, G.; WHITAKER, R.; WEBBER, B. L.. The ecological importance of crocodylians: towards evidence-based justification for their conservation. Biological Reviews, 2020. DOI: 


\section{https://doi.org/10.1111/brv.12594}

SOULSBURY, C. D.; WHITE, P. C. L.. Human-wildlife interactions in urban areas: a review of conflicts, benefits and opportunities. Wildlife Research, v.42, n.7, p.541-553, 2016. DOI: https://doi.org/10.1071/WR14229

TEIXEIRA, C. P.; PASSOS, L.; GOULART, V. D. L. R.; HIRSCH, A.; RODRIGUES, M.; YOUNG, R. J.. Evaluating patterns of human-reptile conflicts in an urban environment. Wildlife Research, v.42, n.7, 2015. DOI: http://dx.doi.org/10.1071/WR15143

TORRES, R. S.. Adaptações evolutivas: aspectos comportamentais, mecanismos de defesa e predação em répteis. 2012.
VERDADE, L. M.. Biologia reprodutiva do jacaré-de-papoamarelo (Caiman latirostris) em São Paulo, Brasil. In: LARRIERA, A.; VERDADE, L. M.. Conservación y Manejo de los Crocodylia de América Latina. Santa Fé: Fundación Banco Bica, 1995. p.57-79.

WALDEZ, F.; VOGT, R. C.. Aspectos ecológicos e epidemiológicos de acidentes ofídicos em comunidades ribeirinhas do baixo rio Purus, Amazonas, Brasil. Acta Amaz., v.39, n.3, p.681-692, 2009. DOI:

https://doi.org/10.1590/S0044-59672009000300025

WWF. Traffic of Species: falling and illegal traffic of species. WWF, 2016.

A CBPC - Companhia Brasileira de Produção Científica (CNPJ: 11.221.422/0001-03) detém os direitos materiais desta publicação. Os direitos referem-se à publicação do trabalho em qualquer parte do mundo, incluindo os direitos às renovações, expansões e disseminações da contribuição, bem como outros direitos subsidiários. Todos os trabalhos publicados eletronicamente poderão posteriormente ser publicados em coletâneas impressas sob coordenação da Sustenere Publishing, da Companhia Brasileira de Produção Científica e seus parceiros autorizados. Os (as) autores (as) preservam os direitos autorais, mas não têm permissão para a publicação da contribuição em outro meio, impresso ou digital, em português ou em tradução. 